\title{
Enlightenment of Medical Hotel on the development of Medical Tourism in China
}

\author{
Lei Jin $^{1,}$, Rui Zhang ${ }^{1}$ \\ ${ }^{1}$ School of Tourism, Hainan Tropical Ocean University, Sanya City, Hainan Province, China \\ a13637608178@163.com
}

Keywords: Medical hotel, Medical tourism, China.

\begin{abstract}
Although health tourism has become a fashionable industry in contemporary society, consumers are no longer satisfied with simple rehabilitation and recuperation. Therefore, a new favorite tourism product that seeking medical treatment overseas has become popular. In this research, the authors analyzes the development status of medical hotel in China based on the literature review and field survey. Furthermore, based on the qualitative research, this study explains that medical hotel is an inevitable trend in the future due to its mixed functions that can help to break the existing reception short-board of medical tourism destinations. This research makes contributions to the theory of medical tourism and also the sustainable development of medical tourism industry.
\end{abstract}

\section{Introduction}

Nowadays, health tourism is a hot and fashion trend of global tourism industry. And it contains two developmental models which are wellness tourism and medical tourism. However, due to the aging of the population, medical technology update, economic crisis and so forth, people are no longer satisfied to wellness travel based on health care with non-emergency treatment, while they prefer to medical travel based on disease cure which has gradually become a new trend of health tourism development.

As for the medical tourism, the World Tourism Organization (UNWTO) defined it as a type of tourism service, taking medical care, disease cure, rehabilitation and recuperation as the main theme[1]. Yet, in a narrow sense, international scholars concerned medical tourism as international medical tourism, which was a phenomenon that people seek medical treatment overseas through the travelling in order to maintain their quality of life[2], including medical, surgical operation and general health examination. Considering the higher required technology, facilities and nursing, as well as a longer recovery time, most patients are prone to seek hospitalization via vocational travel, along with a more comfortable accommodation. Therefore, this needs have greatly promoted the integration of medical industry and tourism industry, bringing a new opportunity and challenge to the economic development of destination countries. According to the statistics[3], the current annual growth rate of global medical tourism has arrived highly at $17.9 \%$, and its market scale is expected to expand from $\$ 10$ billion currently to $\$ 32.5$ billion in 2019. Consequently, the market scale of the global medical tourism has been soaring due to its huge benefits. But, this rapid expansion is also restricted by some factors, especially the existing reception short-board of destination which needs urgent improvement. In the light of a large number of foreign medical tourism research literatures, the author proposed that (1) medical hotel is an inevitable trend of the future development of medical tourism; (2) its complex functions are advantages to break the existing reception short-board of medical tourism destination; (3) the proposed medical hotel is of great significance for the development of medical tourism and hospitality in China.

\section{Medical hotel is an inevitable trend of the future development of medical tourism.}

The Origin of medical tourism. From 18 to 20 Century, medical travel was popular in wealthy man of developing countries who can afford to travel aboard for disease cure. However, this trend has been reversed since the end of 20 Century. In developed countries, there are a plenty of issues 
impacting residents' health care, such as high costs, limited insurance coverage, long waiting time, etc. Thus, they seek treatment in developing countries as its low cost, short queue, advanced technology and facilities, as well as comfortable accommodation and first-class service. In terms of some researches, the cost savings is the primary attracted factor for medical treatment overseas. For instance, taking the medical consumption of American residents as a benchmark, it is remarkably that their medical costs can be cut largely (see Table 1). Howbeit, other scholars suggested that better medical environment and higher quality of care were also important elements for transnational medical travel. Patients from developed countries were more likely to choose the most popular tourism destinations for treatment due to their better climate, natural and cultural attractions which created a more comfortable environment for physical and psychological rehabilitation. Whilst, it was also attributed to the good images of the countries, friendly attitude of medical staff and their high-quality service consciousness and service level that attracted foreign patients.

Table 1. The Medical Cost Savings in Developing Countries

\begin{tabular}{|c|c|}
\hline Medical Tourism Destination & $\begin{array}{c}\text { Medical Cost Savings } \\
\text { (Perception) }\end{array}$ \\
\hline India & $65-90 \%$ \\
\hline Malaysia & $65-80 \%$ \\
\hline Thailand & $50-75 \%$ \\
\hline Turkey & $50-65 \%$ \\
\hline Costa Rica & $45-65 \%$ \\
\hline Mexico & $40-65 \%$ \\
\hline Taiwan & $40-55 \%$ \\
\hline Korea & $30-45 \%$ \\
\hline Singapore & $25-40 \%$ \\
\hline
\end{tabular}

Data Source: http://www.patientsbeyondborders.com/medical-tourism-statistics-facts

Current medical tourism. At present, the world's most popular medical tourism destinations are focused on coastal tourism countries in Southeast Asian, with Thailand as the champion. Since 1980, despite of its international certification (JCI) of medical standards, Bumrungrad International Hospital in Bangkok put forward the integration of medical and tourism as its developmental orientation early in 1997, particularly of its Five-star hospital taking advantages from hotel industry service to create a new service form combining treatment and vacation. This hospital became the originator of international medical tourism services. It provided a series of hotel-style services for medical tourists, including online appointments and consulting, visa, airport, travel agents and language translation. At the same time, its hotel-style lobby and rooms, multi-culture catering and 8:1 medical service ratio, attracted 1.1 million patients of more than 190 countries to go for treatment every year. In 2015, its total medical income was nearly 514 million with a $12.7 \%$ increase compared to the same period in 2014, 50.4\% of which was from international medical tourism[4]. Under the guidance of the hospital, Thailand hotel-style medical tourism soon covered Chiang Mai, Phuket, Samui, etc., which laid the Thai as a leader of medical tourism in Asia. In recent years, South Korea, Malaysia, Philippines and so forth are actively reforming their medical tourism and advocating hotel-style services in hospital to enhance their destination competitiveness.

A new trend of medical tourism. Some studies have shown that international medical tourists are strongly interested in the new emerged medical hotel, and even express their revisiting willingness. What they hope is transnational medical with integrated hotel-style services, referring to schedule, catering, concierge, nursing, valet parking and reliable post-services. Although the spa hotels are all over the world, professional and qualified medical hotel based on "cure" are still limited. Resultly, the integration of medical industry and hotel industry has opened a new chapter for the sustainable development of medical tourism, and medical hotel will be a star of medical tourism in the future. 


\section{The mixed functions of medical hotel are advantages to break the existing reception short-board of medical tourism destinations.}

The concept of medical hotel. The globalization of the health tourism industry has promoted the integration of various resources and industries, where the combination of medical and travel created a new form of services. Since the medical tourism has a reception short-board -- lack of complex medical reception facilities and a high standard of service system, more and more countries are improving the healthcare products and services which are embodied in the hotel industry, resulting in the concept of medical hotel.

Internationally, it is used to call Medical Hotel or Medital, containing medical functions of hospital and comprehensive functions of hotel, to meet multiple needs of medical tourists[5][6]. Beside the impact of the subjective needs, hospitals and hotels can be blended to each other due to their similarities and differences. Their commonness is that both of them are service industries that are keen to focus on their customer experience and hope to enhance their competitiveness through improving customer satisfaction.

By contrast, their core functions are different. To meet guests' demands is the minimum service for hotel, and excellent hotel always devotes itself to exceed customers' expectation via constant improvement of product structure and management mode. Modern hotel offers a full range of services for consumers, including accommodation, catering, shopping, tourism etc. And customers' selective dwell time and types of services are more flexible. Besides, they are also pleasure with leisure vacation and business purpose. In comparison, hospital has a life-saving mission that providing medicine and nursing for patients, but with less selective holiday facilities and anxious and worried patients. Especially for the foreign patients, the remote medical treatment can bring about by high accommodation cost, dietary differences, language barriers and unacquainted environment which undoubtedly increase their psychological burden and are disadvantage to rehabilitation. Therefore, hospital can use the merits of hotel service to make up for emotional care for patients and improve service quality and level, whilst hotel can use the medical functions of hospital to create a new specialized hotel. The combination of these two industries can create new products for contemporary medical tourism, improve economic and service value of tourism destination and promoting the sustainable development of medical tourism.

The superiority of medical hotel. At present, in the medical products, services, facilities and management mode of many share a high similarity, leading to low attractions for medical tourists overseas, because their nature and function are little different with the local hospitals, compared with the obvious comprehensive functions of medical hotel.

AS for the hardware construction, a medical hotel has the basic medical function. Apart from this, the integrated architecture of hotel and hospital including hotel-style lobby, treatment area, accommodation area, dining area, business district, shopping district, rehabilitation area and convalescent area, combining with local natural and human environment, can fully play its holiday and health functions for medical tourists with reduced medical costs, improved convenience and comfort. For instance, Kuala Lumpur in Malaysia, Rio De Janeiro in Brazil and Phuket Island in Thailand are to build their destination brands of coastal medical tourism to enhance competitiveness.

In addition, for the software building, medical hotel focuses on hotel-style service training for medical staff, as well as the improvement of doctor-patient ratio, which is advantageous to enhance friendly service consciousness and the overall affinity of staff. Furthermore, the service of medical coordinators can highlight the synthetic service of medical hotel. From doctor appointment to post-healthcare and feedback, their jobs involve information consulting, visa, air ticket booking, travel services, translation services which can guide consumers get a better holiday medical treatment. This can greatly improve the service efficiency and satisfaction. Finally, it is worth noting that the complexity of medical hotel has put forward higher requirements for the supply chains of relevant industries, which has been a development problem of medical tourism in Malaysia since 1997. Hence, the Malaysia Tourism Bureau (MTPB) advocated the local hospitals, hotels, travel 
agencies and relevant business partners to work together through packaged products, which opened a new situation for its medical tourism development.

Visibly, despite of its basic functions of medical, accommodation, holiday and healthcare, successful medical hotel should also have a function of multi-industrial fusion and create a new platform for medical, accommodation, aviation, insurance, tourism and other industries. This can promote the integration of various resources and industries to provide convenient and efficient products and services for medical tourists, which is also a new challenge for medical tourism industry.

\section{The proposed medical hotel is of great significance for the development of medical tourism and hospitality in China}

Medical tourism in China. Medical tourism industry in China started relatively late. It has not come into the era of medical travel until the 21st century. In the issued "Views on accelerating tourism development' (2009) and "Views on promoting the reform and development of the tourism industry' (2014) by the State Council, it has been clear that medical tourism was a new hot spot of tourism consumption for cultivation and new requirements of its development also has been put forward. In 2016, the "world medical tourism and global health convention' has been hold in Boao City of Hainan Province in China for the first time, which introduced new ideas and vitality for international medical tourism. All of these reflected that medical tourism in China went into its golden period of development.

Advantages and disadvantages of development. Presently, the developmental advantages of Chinese medical tourism contains low price of medical services, adequate human capital, high tourist attraction, combined modern and traditional Chinese medical technology. Nevertheless, compared with neighbour countries, these advantages cannot improve competitiveness. Medical tourism in Thailand, India, Singapore, Malaysia and other countries has shaped their own market scale globally and their experience are relatively mature which is worth learning. From the perspective of tourism supply reform in China now, medical hotel has become the key to mining the growth potential of medical tourism, and its construction cannot be delayed. In 2015, the pilot project of international medical tourism called Hainan Happy City in Boao was officially started. It will build a world-class health corridor where hospital, scientific research base, shopping centre, hotel and hospital are to be integrated, which opens a new chapter for the construction of international tourism island.

Improvement of service quality and level. In addition to the hardware facilities, the development of Chinese medical tourism still need to pay more attention to the cultivation of service quality and improvement of service level. First of all, apart from enhancing policy support, government should make efforts to complete medical tourism service system and standardize corresponding service standards, which can provide policy basis for the construction of medical hotel service. Secondly, in order to consolidating the industrial responsibilities of medical hotel, legal system should be strengthened to prevent ethic and quality problems effectively. Thirdly, taking medical hotel as a platform, reinforcement of the co-operation of multi-industries via resources integration can expand the functions of medical hotel to achieve win-win" benefits from medical tourism. Fourth, it is also crucial that to build home-like atmosphere for medical tourists by means of improving the service consciousness and friendly attitude of medical hotel staff. Lastly, it is expected to set up medical hotel service process and quality management system with international standards via international certification.

\section{Acknowledgement}

This research was financially supported by the Project of Hainan Provincial Social Science Union (Grant No: HNSK (YB) 15-16) . 


\section{References}

[1] Chen, P.-T., Kung, R.-H., Huang, M. Y., Chen, F.-D., \& Pei, L. (2012). Exploring the medical tourism development barriers and participation willingness in taiwan: An example of mainland tourist. Proceedings of World Academy of Science, Engineering and Technology, 68.

[2] Connell, J. (2006). Medical tourism: Sea, sun, sand and $\cdots$ surgery. Tourism Management, 27(6), 1093-1100.

[3] http://www.transparencymarketresearch.com/medical-tourism.html, Medical Tourism Market (India, Thailand, Singapore, Malaysia, Mexico, Brazil, Taiwan, Turkey, South Korea, Costa Rica, Poland, Dubai and Philippines) - Global Industry Analysis, Size, Share, Growth, Trends and Forecast, 2013 - 2019

[4] http://bh.listedcompany.com/misc/AR/20160405-bh-ar2015-en.pdf, Bumrungrad International Hospital Annual Report 2015

[5] Han, H., \& Hyun, S. S. (2014). Medical Hotel in the Growth of Global Medical Tourism. Journal of Travel \& Tourism Marketing, 31(3), 366-380.

[6] Whittaker, A., \& Chee, H. L. (2015). Perceptions of an "International Hospital" in Thailand by Medical Travel Patients: Cross-cultural Tensions in a Transnational Space. Social Science \& Medicine, 124, 290-297. 